\title{
Educación intercultural: desde el desarrollo de competencias del profesorado hasta las trayectorias vitales del estudiantado internacional
}

\author{
Diana Jareño-Ruiz, Pablo de-Gracia-Soriano, Sergio Andrés-Cabello, Alícia Villar-Aguilés, \\ Mar Venegas y José Beltrán-Llavador ${ }^{1}$
}

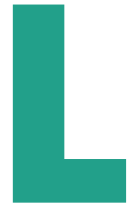

a situación de crisis sanitaria mundial, donde las instituciones y sistemas educativos se han visto alterados por las diferentes políticas restrictivas para controlar la propagación del virus, debe complementarse con la riqueza de las producciones científicas realizadas hasta el momento. Es por ello que, en este número, la RASE continúa ofreciendo un espacio para la reflexión sobre temas de interés para la sociología de la educación, como son la formación, las desigualdades y sus efectos en el ámbito socioeducativo. En concreto, la educación intercultural se ha seleccionado como eje vertebrador de este número misceláneo debido a la pluralidad de orígenes geográficos y temáticas abordadas.

Este número reúne los trabajos realizados por once personas, seis autoras y cinco autores, y se estructura en cinco artículos y dos reseñas de libros. A través de dichas contribuciones se pueden recorrer las experiencias educativas por distintas coordenadas geográficas: España, Escocia, Chile y Argentina.

El primero de los trabajos que recoge este número es «Hacia una evolución de la eficacia intercultural en el profesorado en formación», cuyas autoras son Diana Tatiana Íñiguez-Berrozpe, Ainhoa Valero-Errazu y Gisela Redondo-Sama. Se parte del análisis del concepto de «eficiencia intercultural» en relación con la profesión docente. Para ello, a partir de una muestra de estudiantes del último curso del Grado de Magisterio de Educación Infantil y Magisterio de Primaria y del Máster de Profesorado de Secundaria, se evalúa la incidencia de factores sociodemográficos en los índices de eficiencia cultural, tras la aplicación de Multicultural Efficacy Scale de Guyton y Wesche (2005).

Partiendo de la interculturalidad de la primera contribución de este número, el resto de artículos centran su atención en diferentes niveles de sistemas educativos de distintos países: Escocia, Chile y Argentina. Conocer la heterogeneidad de las enseñanzas internacionales y de sus instituciones se convierte en una cuestión imprescindible para mejorar en cada una de las prácticas concretas a desarrollar en el ámbito educativo.

El segundo de los trabajos ha sido elaborado por Thiago Bogossian con el título «'I Can’t Get the Practical Hours': Care, Course Choice and Role Conflict Among Student-Mothers in Higher Education in Scotland». Este trabajo permite conocer la situación de las madres-estudiantes, como así denomina a su población objeto de estudio el propio autor, que concilian la vida personal y laboral con sus estudios

\footnotetext{
1 Diana Jareño-Ruiz, Universidad de Alicante, diana.jareno@gcloud.ua.es; Pablo de-Gracia-Soriano, Universidad de Alicante, pablo.dgsoriano@ua.es; Sergio Andrés-Cabello, Universidad de La Rioja, sergio.andres@unirioja.es; Alícia Villar-Aguilés, Universitat de València, alicia.villar@uv.es; Mar Venegas, Universidad de Granada, mar.venegasm@gmail.com; José Beltrán-Llavador, Universitat de València, jose.beltran@uv.es.
} 
superiores en Escocia, evidenciando a través de una investigación cualitativa los retos que suponen la elección de continuar con sus estudios. Se detiene en el apoyo que reciben por parte de los centros, la ayuda de su entono familiar, la oferta de materias y horarios, entre otros, y todo ello dando voz a un grupo de estudiantes que se salen de la «norma», que son minoría en las enseñanzas superiores.

Tras detenerse en experiencias de madres-estudiantes del norte de Europa, se recorre un largo camino para conocer las «Experiencias y aspiraciones educacionales de estudiantes secundarios de distinta clase social en Valparaíso, Chile». Su autor, Javier Donoso-Bravo, nos narra las aspiraciones educacionales y ocupacionales entre el estudiantado y cómo a pesar de sus diferentes experiencias socioeducativas, por sus condiciones sociales desiguales, expresan grandes similitudes. La finalidad de este trabajo es avanzar en la comprensión de la desigualdad socioeducativa en Chile, e identificar cómo la clase social y la dependencia administrativa de los colegios perpetúan la segregación escolar y social a pesar de la resistencia del alumnado.

En los dos artículos que siguen el salto geográfico que se da es más corto. Desde la realidad chilena nos acercamos a dos casos de su país vecino (Argentina), poniendo el foco en dos niveles educativos diferentes como son los estudios de formación profesional y los estudios universitarios.

Marcelo Fabian Delfini, María Ana Drolas y Juan Sebastian Montes Cató, han titulado su trabajo «La formación profesional en la construcción de trayectorias laborales. Estudio sobre sectores productivos en Argentina». Teniendo presente los testimonios de directivos, profesores y estudiantes se muestra la relevancia que las enseñanzas educativas de formación profesional tienen para la inserción laboral de sus estudiantes y el desarrollo económico de sus territorios. Para ello, desde una estrategia metodológica cualitativa, se han acercado a cuatro de las familias profesionales más demandas en Argentina con el propósito de resaltar la sobredimensión de las lógicas productivas sobre las educativas en la planificación y diseño de la formación profesional en su sistema educativo.

El último de los artículos de este número analiza los Proyectos de Desarrollo Tecnológico y Social (PDTS) que se llevan a cabo en las universidades argentinas. Mauro Alonso sitúa el foco en los recursos institucionales que se ponen a disposición de los académicos para promover un mayor uso del conocimiento y una mejora en la enseñanza. Descubre así la importancia de las novedades de estos programas, que van desprendiéndose de algunas lógicas tradicionales de la academia.

El presente número de la RASE incorpora dos reseñas sobre obras de especial relevancia como son: Interculturalidad y cultura de la diversidad en el contexto universitario (2018), de Dolores Pareja de Vicente y Juan Olivencia, y El nuevo contrato social entre generaciones. Elogio de la profiguración (2021), de Fidel Molina-Luque.

La primera de las reseñas, realizada por Hélia Bracons, nos presenta los resultados de un proyecto que surge de un proyecto de innovación educativa de la Universidad de Málaga que tiene como finalidad ofrecer una mirada pedagógica reflexiva y crítica sobre la diversidad cultural, la formación intercultural de los futuros profesionales de la educación, tal y como también analiza el primero de los artículos de este número, y las propias actitudes de profesorado universitario hacia la educación intercultural como propuesta de acción educativa.

Por último, para cerrar este número, la reseña que realiza Paquita Sanvicén Torné sobre la reciente obra publicada por Fidel Molina-Luque, recuerda la necesidad de crear un nuevo contrato social entre gene- 
raciones para conseguir el bienestar, tal y como la actual crisis ha puesto de manifiesto. La solidaridad, el diálogo, el altruismo y, por supuesto, la educación, se convierten en las claves de una sociedad más justa y más feliz, tal y como se indica en el trabajo.

Precisamente, los valores de diálogo intercultural son los que marcaron las intervenciones de la Conferencia Internacional «Sociology of Education in Southern Societies: a Step Forward», celebrada (on line) en Milán, del 25 al 27 de mayo de 2021, con el concurso de la Associazione Italiana di Sociologia dell'Educazione (AIS), Società Italiana di Sociologia della Pedagogia (Siped), Associazione Francese di Sociologia (AFS), Associação Portuguesa de Sociologia (APS) y Federación Española de Sociología (FES). Esta Conferencia reafirma nuestro compromiso académico, con la mirada desde el Sur, de avanzar en la mejora de nuestras sociedades.

En esta dirección, desde el equipo editorial de la RASE seguimos trabajando para obtener y producir estos espacios de encuentro, de aprendizaje e intercambio. 